\title{
Erratum to: The mediating role of intercultural wonderment: connecting programmatic components to global outcomes in study abroad
}

\author{
Mark E. Engberg ${ }^{1}$ - T. J. Jourian ${ }^{1}$. \\ Lisa M. Davidson ${ }^{1}$
}

Published online: 16 July 2015

(C) Springer Science+Business Media Dordrecht 2015

\section{Erratum to: High Educ \\ DOI 10.1007/s10734-015-9886-6}

In the original publication of the article, in Fig. 2, the line from "Classroom Reflective Assignments" to "Knowledge T2" should be broken rather than in solid, and the coefficient ".02" should not be associated with any asterisks. The corrected figure is given below.

The online version of the original article can be found under doi:10.1007/s10734-015-9886-6.

Mark E. Engberg

mengber@luc.edu

1 Higher Education Program, Loyola University Chicago, 820 N. Michigan Ave, Lewis Towers,

Chicago, IL 60611, USA 


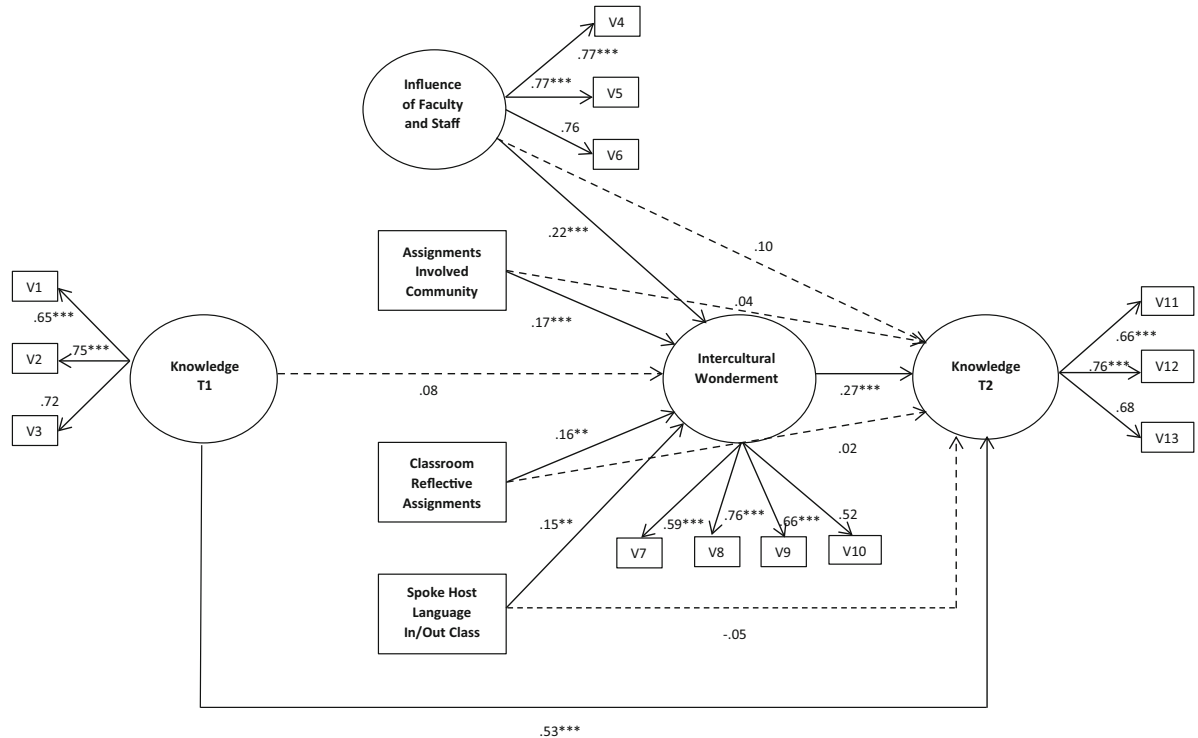

Fig. 2 Summary of the standardized path coefficients for the full structural model: $\chi^{2}(85$, $n=510)=157.64$, NFI $=.93, \mathrm{NNFI}=.95, \mathrm{CFI}=.97, \mathrm{SRMR}=.04$, and RMSEA $=.04$. Significant levels are indicated by the following: $* p<0.05$, $* * p<0.01, * * * p<0.001$. Insignificant paths are indicated with dashed line. The following factor loadings were set to one: V3, V6, V10, and V13. Covariances, error terms, and disturbances are not shown in the model 